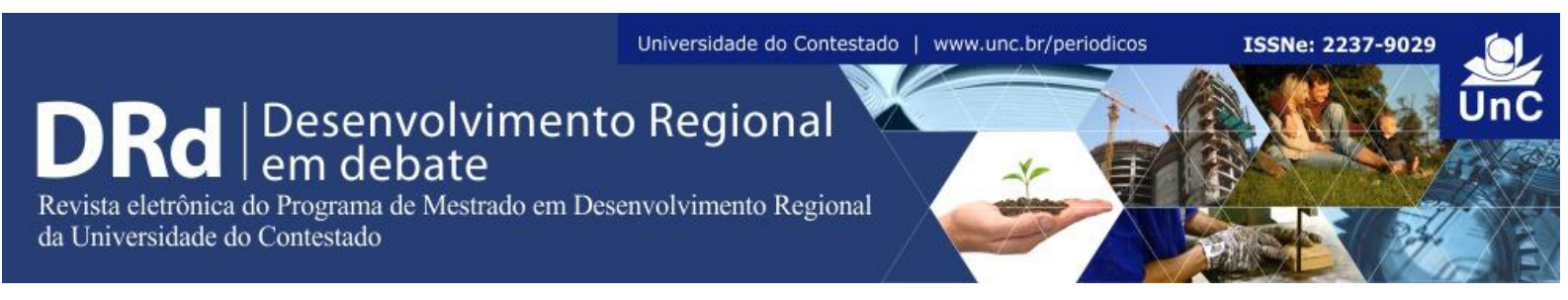

\title{
O USO DO CERRADO AMAPAENSE E OS RECURSOS VEGETAIS
}

\author{
Gilberto Ken Iti Yokomizo ${ }^{1}$ \\ Liliane do Nascimento Costa ${ }^{2}$
}

\begin{abstract}
RESUMO
O desenvolvimento regional na Amazônia é tema de grandes discussões, baseado na exploração de madeira na floresta densa de terra firme, notando-se que o Cerrado presente na região Norte do País é pouco conhecido e discutido. Desta forma, o objetivo deste artigo é mostrar as formas de uso atual, ocupação e possíveis consequências da utilização do Cerrado amapaense, devido parcela desprezível a ser protegida em Unidades de Conservação, podendo haver perda de materiais genéticos e principalmente por estar em condições climáticas tropicais, além do uso potencial e das políticas públicas existentes. A metodologia utilizada baseou-se na estrutura de um ensaio teórico, utilizando dados secundários, através de pesquisa bibliográfica nos seguintes locais: biblioteca "Dr. Dorival Pimentel" da Embrapa Amapá, biblioteca Central da Universidade Federal do Amapá (UNIFAP), biblioteca da Secretaria de Estado do Meio Ambiente (SEMA) do Amapá, biblioteca do Instituto de Pesquisas Científicas e Tecnológicas do Estado do Amapá (IEPA) e internet. Conclui-se que o uso atual é baseado na silvicultura e pecuária e, pouco com agricultura, havendo elevado potencial de exploração para produção de alimentos, sendo fundamental a adoção de técnicas de manejo, material genético apropriado e existência de políticas públicas de gestão e fiscalização, o que ainda é incipiente e pouco aplicado, associando desenvolvimento com conservação ambiental.
\end{abstract}

Palavras Chaves: Cerrado amapaense. Economia do Amapá. Desenvolvimento Sustentável.

\footnotetext{
${ }^{1}$ Possui graduação em Engenharia Agronômica pela Universidade de São Paulo (1991), Mestrado em Agronomia (área de concentração em Genética e Melhoramento de Plantas) pela Universidade de São Paulo (1994). Doutorado em Agronomia (área de concentração em Genética e Melhoramento de Plantas) pela Universidade de São Paulo (1999). Pós-Doutor em Agronomia (área de concentração em Genética e Melhoramento de Plantas) pela Universidade de São Paulo (2008). Pesquisador da Embrapa Amapá. Amapá. Brasil. E-mail: gilberto.yokomizo@embrapa.br

${ }^{2}$ Bióloga formada pela Universidade Federal do Amapá em Ciências Biológicas Licenciatura, Mestre em Desenvolvimento Regional e Políticas Públicas ambientais na linha de pesquisa: Meio Ambiente, Desenvolvimento sustentável e cultura. Faculdade de Macapá (FAMA). Amapá. Brasil. E-mail: lilianevini@hotmail.com
}

DRd - Desenvolvimento Regional em debate (ISSNe 2237-9029) v. 6, n. 3, p. 164-177, nov. 2016. 


\title{
THE USE OF CERRADO AMAPAENSE AND VEGETABLE RESOURCES
}

\begin{abstract}
The regional development in the Amazon is the subject of much discussion, based on the wood exploitation from upland dense forest, noting that the savannah present in the north of the country is little known and discussed. Thus, the objective of this article is to present the forms of use, occupation and possible consequences of the use of Amapá savannah, due negligible portion be protected in conservation units, with possible loss of genetic materials and especially to be in tropical conditions, in addition to the potential use and existing public politics. The methodology used was based on the structure of a theoretical test, using secondary data through literature search in the following locations: Library "Dr. Dorival Pimentel " from Embrapa Amapá, Central Library of the Federal University of Amapá (UNIFAP) Library from Secretariat of Environment of Amapá State (SEMA), library of the Scientific and Technological Research Institute of Amapa State (IEPA) and internet. Was concluded that the current use is based on forestry and livestock and some still in agriculture, there is high potential for exploration for food production, it is essential to adopt management techniques, appropriate genetic material and the existence of public policy management and supervision, associating development with environmental conservation.
\end{abstract}

Keywords: Amapá savannah. Economy of Amapá. Sustainable Development.

\section{INTRODUÇÃO}

O bioma Cerrado, encontrado nos estados do Mato Grosso, Mato Grosso do Sul, Goiás e Tocantins, ocupa aproximadamente um quarto do território brasileiro, cerca de 200 milhões de hectares, sendo que deste total cerca de $40 \%$ do espaço foi convertido em áreas de pastagens e agricultura nas últimas três décadas (SANO et al., 2008). O Cerrado abriga um rico patrimônio de recursos naturais renováveis adaptados às duras condições climáticas, edáficas e hídricas que determinam sua própria existência (MAROUELLI, 2003), mas ao qual ainda é dado pouca importância. Apresentando também uma rápida expansão de uso, sendo que de acordo com Matos e Pessôa (2011), esse processo veio apoiado no tripé da ciência, da tecnologia e da informação, reestruturando o espaço agrário da região central do Brasil.

O estudo do uso do Cerrado e seus recursos naturais busca ampliar os conhecimentos sobre este importante ecossistema, visando constatar o que tem sido feito neste bioma e quais os seus principais usos e, o que realmente é realizado para preservar este bioma. De acordo com os dados de Klink e Machado (2005, p.145), “[...] o Cerrado brasileiro apresenta uma dimensão de aproximadamente 2,04 milhões de quilômetros quadrados, o que equivale a cerca de $22 \%$ do território nacional, ou seja, é o segundo maior bioma do Brasil, somente superado pela Amazônia. No Estado do Amapá, o ocupa cerca de 900.000 hectares, o que corresponde a 6,9\% da superfície deste Estado" (MELÉM JÚNIOR et al., 2008). O Cerrado amapaense nesse contexto está inserido nos municípios de Macapá, Santana, Porto Grande, Itaubal e Calçoene, com 374 km de extensão. 
A conservação da biodiversidade é inserida neste contexto, pois os recursos naturais são um patrimônio a ser mantido, por representar fontes futuras com possibilidade de uso e manutenção do equilíbrio ambiental. De acordo com a inserção gradual da temática ambiental nas inúmeras discussões em torno do crescimento econômico que já foram propostas e realizadas, revela-se vigente a necessidade de considerar com muita atenção e urgência o sustentáculo da economia mundial, que são os referidos recursos e a manutenção de um ambiente sadio e equilibrado.

Sendo que o Amapá é considerado como uma das últimas fronteiras agrícolas e, portanto, a produção agrícola em grande escala encontra-se ainda em processo de adaptação, transportando-se metodologias desenvolvidas em outras regiões, principalmente do CentroOeste do Brasil, devendo-se atentar em adotar as boas práticas existentes e evitar os problemas causados pela agricultura comercial já conhecidos, conseguindo desta forma obter uma produção sustentável de baixo impacto ambiental, conservando as belezas naturais do Estado. São prementes as pesquisas com milho, arroz, soja, gramíneas para pastagem e coberturas verdes para a recomendação de cultivares adaptadas às condições edafoclimáticas regionais, mas também devem existir estudos relativos a adubação, irrigação, fitossanidade, época de semeadura, controle de invasoras, manejo de cobertura verde, de forma participativa com os agricultores. Adicionalmente deve-se buscar soluções quanto aos aspectos fundiários e de infraestrutura no Amapá, além de desenvolvimento de políticas públicas adequadas (YOKOMIZO, 2015).

Este artigo propõe analisar a utilização atual do Cerrado amapaense e suas principais formas de ocupação, que aconteceram e/ou vem acontecendo, bem como identificar os principais agentes responsáveis e consequências desse processo. Além de possibilitar e subsidiar novas propostas de uso adequado à realidade local, pois as peculiaridades do Cerrado amapaense tem que ser levadas em consideração para delimitar melhor as áreas destinadas ao uso sustentável, devido às condições climáticas tropicais. Para isto, discorrer-seá primeiramente sobre a política pública existente, que ainda não está formatada, seguida por apresentação das atividades socioeconômicas desenvolvidas no Cerrado amapaense, com uso basicamente apoiada na silvicultura, insipiente pecuária de base tecnológica baixa e cultivo agrícola de grãos em crescimento; posteriormente sobre seu potencial para o desenvolvimento do Amapá, apresentando informações sobre suas características edafoclimáticas, infraestrutura, localização estratégica em relação ao mercado externo, assim como também o real potencial de produção tanto de grãos, como de frutíferas, pecuário e de essências florestais e terminando abordando o uso sustentável do mesmo, visando principalmente a manutenção deste bioma e de seus recursos vegetais, devido a apenas 6,9\% do Cerrado amapaense estar inserido em algum tipo de unidade de conservação ambiental, o que pode permitir a destruição deste ecossistema no Estado.

\section{MATERIAL E MÉTODOS}

O presente artigo, em forma de ensaio teórico, se caracteriza como uma pesquisa bibliográfica. Quanto à abordagem, em alinhamento à classificação proposta por Sampieri et al. (2013), essa pesquisa se caracterizou por um enfoque qualitativo. Esse enfoque visa a 
dispersão dos dados, buscando entender o fenômeno de estudo em seu ambiente usual, sem generalizar os resultados, inferindo sobre a situação vivenciada regionalmente.

Quanto aos fins, trata-se de uma pesquisa descritiva, pois esse estudo pretende coletar informações de forma independente, integrando essas informações para descrever como se manifesta o fenômeno proposto no título deste artigo, sem indicar como as variáveis se relacionam (SAMPIERI et al., 2013).

Quanto aos meios, é uma pesquisa bibliográfica, realizada por meio de um estudo de caso, pois toda a bibliografia existente, especificamente para o Cerrado amapaense, com possibilidade de consulta foi obtida. Yin (2010) elucida que o estudo de caso é um método de investigação empírico que verifica um fenômeno contemporâneo dentro de seu contexto, especialmente quando os limites entre fenômeno e contexto não são bem definidos. Conforme o autor, a coleta de dados para esses estudos pode se basear em muitas fontes de evidências: documentação, registro em arquivos, entrevistas, observação direta, observação participante e artefatos físicos. Aqui foram empregadas as duas primeiras evidências e, a terceira, quando possível.

Para esse estudo foram utilizados dados secundários, que foram as interpretações de dados primários. Os dados secundários foram obtidos através das análises de documentos, artigos publicados e sítios na Internet (COOPER; SCHINDLER, 2011). Segundo Cervo et al. (2007), a pesquisa documental ou bibliográfica busca explicar um problema baseado em referências teóricas, sejam elas oriundas de livros, artigos publicados, dissertações, teses, anais de congressos e revistas especializadas que tratam do tema. São realizadas buscas e leituras intensas acerca do tema em questão a fim de se colher o máximo de informações possíveis e tentar exaurir os resultados de busca. Segundo Lakatos e Marconi (2008), o intuito de uma pesquisa bibliográfica é colocar o pesquisador em contato com o que foi produzido sobre determinado assunto, inclusive através de conferências. Para Gil (2011) "A principal vantagem da pesquisa bibliográfica reside no fato de permitir ao investigador a cobertura de uma gama de fenômenos muito mais ampla do que aquela que poderia se pesquisar diretamente".

Os locais de coleta das informações foram: biblioteca "Dr. Dorival Pimentel" da Embrapa Amapá, biblioteca Central da Universidade Federal do Amapá (UNIFAP), biblioteca da Secretaria de Estado do Meio Ambiente (SEMA) do Amapá, biblioteca do Instituto de Pesquisas Científicas e Tecnológicas do Estado do Amapá (IEPA) e internet.

A forma de interpretação foi buscar o entendimento da situação e propor alternativas de inter-relacionar o Cerrado do Amapá com os possíveis resultados do seu uso, baseado numa discussão descritiva, com abordagem descritiva-discursiva, por meio de pesquisa documental. $\mathrm{O}$ aspecto descritivo-discursivo é observado na discussão do Cerrado e seu potencial de utilização para os personagens envolvidos apresentando, assim, uma descrição da amostra analisada, ou seja, do que foi obtido na fase de levantamento documental. Conforme Gil (2011), uma pesquisa deste tipo tem como objetivo primordial a descrição das características de determinada população, fenômeno ou o estabelecimento de relações entre variáveis. 


\section{RESULTADOS E DISCUSSÃO}

\subsection{ATIVIDADES SOCIOECONÔMICAS DESENVOLVIDAS NO CERRADO AMAPAENSE}

No Cerrado brasileiro a economia é fortemente apoiada na produção de grãos. Até 1990, a atividade cresceu $62 \%$ em nove anos, principalmente devido à abertura de novas fronteiras. Entretanto, a atividade vem experimentando uma diminuição nos últimos anos, com ritmos menos acentuados na expansão territorial. Em contrapartida, dados começam a mostrar os efeitos de melhoria no padrão tecnológico da produção, principalmente devido a técnicas de cultivo (BRASIL. MMA, 2002, p. 198).

O primeiro e principal uso do Cerrado amapaense iniciou através da implantação da Amapá Florestal e Celulose S.A. (AMCEL) em 1976 no município de Porto Grande, com a plantação de Pinus, visando fornecer cavaco de pinus para fábrica de celulose do Complexo Industrial do Jarí, que após 1997 ampliou seu mercado para o Japão, União Européia (Suécia, Portugal e Espanha) e Estados Unidos da América (PORTO, 2007, p.134). A atuação, no setor industrial, da empresa Champion Papel e Celulose Ltda., compradora do patrimônio da AMCEL, em 1996, tem sido bastante criticada no que se refere a intenção da plantação de mais de 100 mil hectares de eucaliptos nas áreas de Cerrado do Amapá. Tal objetivo tem sido alvo de críticas por representantes governamentais, seja para defender o uso da terra no incentivo à agricultura local e manter a população no campo, seja nas discussões sobre os impactos ambientais dessa cultura no Estado (PORTO, 2003), contudo a produção de cavacos de madeira para extração de celulose ainda é o principal uso.

Observa-se que o uso do Cerrado nos últimos anos tem se tornado cada vez mais frequente, pois pesquisas na área de melhoramento genético vegetal tem disponibilizado cultivares adaptados às condições edafoclimáticas do Cerrado para utilização pelos produtores rurais e empresas agrícolas. O Amapá também possui este ecossistema cuja atividade de produção agrícola também tem se estabelecido, dando base para o surgimento de novas tendências para a agricultura no estado. O trabalho de Oliveira $(2009$, p.79), discorre sobre a questão, expondo que o Cerrado amapaense já apresenta algum tipo de cultivo agrícola para produção de grãos e que a proximidade destes cultivos com a rodovia BR 156 facilitaria a escoação da produção.

O Amapá apresenta uma economia que em seu contexto histórico abrange as atividades extrativistas tanto vegetal quanto mineral, além de uma insipiente agropecuária. A maioria destas atividades são desenvolvidas no Cerrado, onde a agricultura acompanha as margens das rodovias, em sua maioria desenvolvida por agricultura familiar. A pecuária abrange as pastagens nativas e campos inundáveis, sendo que a vegetação natural constitui a principal fonte alimentar dos rebanhos bubalinos e bovinos. Nesses ambientes, a pecuária é desenvolvida de forma extensiva, tanto em grandes como em pequenas propriedades (PPCDAP, 2010).

A agricultura nos Cerrados somente será sustentável se for capaz de competir com outras regiões brasileiras e, mesmo, com a de outros países. Atualmente, segundo Marouelli

DRd - Desenvolvimento Regional em debate (ISSNe 2237-9029) 
(2003), é evidente que o Cerrado possui vantagens comparativas na produção agrícola, quando comparado a outras regiões. Uma das características favoráveis para a produção agrícola no Cerrado brasileiro é o solo, que é em sua maior extensão do tipo Latossolo, estando presente em 46\% da área do bioma (SANTOS et al., 2010, p.7), além da presença de chuvas bem definidas, relevo do solo plano, insolação, entre outros.

Observa-se que a economia amapaense nos últimos tempos é caracterizada pelo agroextrativismo e a agropecuária de baixa tecnologia. Neste contexto, o extrativismo vegetal é um segmento de suma importância para a economia do Amapá. Seu potencial de exploração é, entretanto, muito maior do que é efetivamente realizado hoje. O potencial do extrativismo está correlacionado à vasta extensão do território estadual contendo elevada biodiversidade de espécies vegetais. Outro aspecto importante a ser considerado na análise da agricultura amapaense é a incorporação das áreas de Cerrado aos sistemas de cultivo (PPCDAP, 2010).

No Amapá existem 130 mil hectares de Cerrado ocupado por atividades de agricultura familiar, sendo que 16,9 \% eram destinados a pastagens, 49,7 \% contém florestas e 28,3\% são ocupadas por lavouras. Mesmo com uma pequena participação em áreas destinada às lavouras, a agricultura familiar é responsável por parte considerável de alguns produtos alimentícios como a farinha de mandioca. O Estado foi o que menos declarou investimentos decorrentes de crédito rural, no valor de R \$ 650 milhões (RURAP, 2012).

A agricultura no Estado do Amapá envolve principalmente a produção para a subsistência local, sendo que a agricultura familiar predomina na maioria das áreas produtivas da região. Segundo o IBGE, o conceito mais aceitável é que a atividade comercial de agricultura familiar é aquela dirigida pelo próprio produtor rural e que utiliza mais a mão-deobra familiar que a contratada.

De acordo com estudos realizados por Oliveira (2009, p.73), 59\% do Cerrado amapaense encontra-se apto para a produção agrícola, sendo que $39 \%$ estão ocupados pela silvicultura, restando $20 \%$ para a produção temporária, que seriam principalmente o feijão caupi, o milho e a soja.

O Cerrado amapaense passará a ser um ecossistema fortemente pressionado por diversas atividades, que vão desde a expansão dos principais eixos urbanos do estado, agricultura familiar e espaços de uso tradicional de comunidades quilombolas, até grandes projetos de silvicultura e agronegócio que estão surgindo (OLIVEIRA, 2009). A proposta de desenvolvimento agrícola deste ambiente busca apresentar visões alternativas para o processo de uso, manejo e agricultura da área mais diretamente pressionada pela ação humana no estado.

A EMBRAPA possui um projeto Convênio Cerrados: Parceria, Tecnologia e Qualidade no Cerrado Centro-Oeste, que abrange os estados de Goiás, Minas Gerais, Mato Grosso, Distrito Federal, Bahia, Tocantins e Maranhão, o qual visa auxiliar na alta produtividade, qualidade e manutenção da soja produzida pelos agricultores desta região. A introdução de técnicas que auxiliem a produção é necessária para melhorar a qualidade, e por esta razão o Amapá apresenta potencial para inserção de projetos semelhantes, assimilando as tecnologias desenvolvidas no citado projeto (BRASIL. MMA, 2003).

A atividade agrícola, embora seja considerada de maior importância socioeconômica, uma vez que é o sustento básico de qualquer economia, no Amapá ainda é realizada em

DRd - Desenvolvimento Regional em debate (ISSNe 2237-9029) 
pequena escala, sendo considerada uma cultura apenas para subsistência. A participação no abastecimento do mercado local é insignificante, não havendo excedente para exportação, ao contrário há importação em quase a totalidade do que é consumido internamente (PPCDAP, 2010).

O fortalecimento da economia no Estado do Amapá, apoiada no desenvolvimento do agronegócio, basicamente todo realizado no Cerrado, pode ser considerado como irreversível, contudo pontos fracos existentes como um processamento industrial baixo ou inexistente; altos custos de produção e comercialização; baixa capacidade de gestão empresarial; baixa qualificação da mão-de-obra, baixa condição de estrutura e infraestrutura instalada, dificuldade de regularização fundiária, devem ser urgentemente solucionados, contudo existem os pontos fortes como sua posição estratégica em relação ao mercado consumidor interno e externo, menor custo de produção nas atividades em que tem vantagens comparativas; grande estoque de terras prontas para integrar o processo produtivo; condição ecológica favorável ao agronegócio, baixo risco de passivo ambiental, programas de financiamento nos bancos da região; programas do Governo Federal que favorecem a região (ABC e outros), facilidade de implantação de programas de qualificação da mão-de--obra, organização social e jurídica (Cooperativa dos Produtores Agrícolas do Cerrado Amapaense) dos participantes da cadeia de produção agropecuária ativa no Estado, facilidade de ordenação, regularização e ocupação fundiária (ALVES; CASTRO, 2014a; 2014b), são condicionantes que estimulam este esforço em se desenvolver o Amapá com base neste tipo de produção.

Apesar de parte Cerrado amapaense ser utilizado para a produção de pinus e eucalipto, com menor escala dos grãos de soja, milho e arroz, com concentração às margens da rodovia federal BR 156, a partir de Macapá até as proximidades do $\mathrm{km} 50$, estando presente também presente no município de Itaubal (MELÉM JUNIOR et al., 2003), teve-se no ano de 2002 introduzido o cultivo de arroz em larga escala nos Cerrados de Itaubal, despertando o conhecimento e o interesse de produtores do sul do país em adquirir terras de Cerrado visando a produção de soja, o que abriria perspectivas para o surgimento de nova frente agrícola em território amapaense (DOMINGUES et al. 2004).

No ano de 2011, o número de produtores na região do cerrado amapaense não era grande, segundo Yokomizo (2015) que observou a presença de 20 proprietários que desenvolviam algum tipo de atividade em suas áreas, sendo que destes, quatro não quiseram se manifestar sobre que cultivo realizavam, nove citaram que atuavam na produção de frutas e hortaliças e sete com a produção de grãos. Passando de uma área cultivada de 2.500 para quase 10.000 hectares, entre os anos de 2012 e 2013 (CASTRO et al., 2014), de acordo com a Cooperativa de Agricultores do Cerrado Amapaense, a produção de grãos no Estado, em 2013, contabilizou 18000 toneladas de soja, 8000 toneladas de milho, 22000 toneladas de arroz e 700 toneladas de feijão (SUPERTI; SILVA, 2015).

Conforme projeção da Cooperativa dos Produtores Agrícolas do Cerrado Amapaense (Coopac), a tendência é de crescimento a cada ano da produção de soja no Amapá, processo recente no setor rural do Estado, causado por médios produtores vindos de outras regiões do país, entre gaúchos, paranaenses, mineiros e matogrossenses. A Coopac estima que dos cerca de 50 cooperados, pouco mais da metade já se encontra instalada do Amapá e os demais estão se preparando para plantar grãos no Estado. Isso também explica o aumento na produção de 
outros cultivos como arroz, feijão (caupi) e milho, também registrado pelo IBGE (PEDRADA; SANTOS, 2014).

\subsection{POTENCIAL DO CERRADO NO AMAPÁ PARA O DESENVOLVIMENTO REGIONAL}

De acordo com Oliveira (2009, p.73) e também Alves e Castro (2014b), o Cerrado amapaense possui qualidades de relevo, representando as mais importantes áreas mecanizáveis; vegetação e proximidade de estradas de ferro e rodovias, delimitando as regiões com maior potencial de utilização. Por ser uma área de elevada precipitação pluviométrica, possui características intrínsecas que o distingue do Cerrado da região CentroOeste do País, possibilitando um período de cultivo suficiente para duas safras agrícolas por ano na mesma área, sem uso de irrigação complementar, com baixa probabilidade de insucesso na safrinha em decorrência de veranicos (ALVES; CASTRO, 2014b). A região de abrangência do Cerrado possui cerca de $300 \mathrm{~km}$ asfaltados pela presença da rodovia BR 156, além de existir a estrada de ferro Santana-Serra do Navio, com cerca de $200 \mathrm{~km}$ de extensão, ou seja, uma infraestrutura de transporte interessante (YOKOMIZO, 2004).

Uma das atividades mais promissoras a ser desenvolvida é o cultivo de grãos no Amapá, que é viável e muito importante para o desenvolvimento do estado, aspecto verificado em 2004 por Yokomizo (2004) para plantio da soja no Cerrado do Amapá, contudo os custos eram elevados devido ao preço dos insumos, esperando-se que, com a criação da demanda, houvesse queda nos preços; mesmo assim observou-se saldo positivo, ou seja, lucratividade naquela época.

O Amapá possui uma localização geográfica privilegiada, ou seja, está mais próximo dos centros industrializados como a União Europeia. Este é mais um dos aspectos favoráveis para a produção de grãos no estado em relação aos outros estados brasileiros produtores. Além do solo, com textura franco argilosa que permite sua manutenção hídrica e fornecimento de nutrientes, sem lixiviação imediata após a aplicação de adubação mineral, o clima da região em questão é apropriado para o cultivo de grãos e também o relevo é adequado com extensas áreas planas (YOKOMIZO, 2004).

No manejo do Cerrado amapaense tem que ser levado em consideração as características específicas nele existentes, o qual difere das áreas tradicionais de cultivo do Centro-Oeste do Brasil. A falta de inserção deste bioma em uma unidade de conservação e seu uso sem precedentes, expõe-no a degradações ambientais irreversíveis, ocasionando perda de biodiversidade e modificação das condições edafoclimáticas regionais (SETEC, 2014).

Atualmente, para realizar-se a produção em grande escala faz-se necessário um estudo prévio com as próprias empresas agrícolas de produção, os pequenos agricultores, moradores tradicionais sem produção agrícola, instituições de pesquisas estaduais e nacionais, Universidades e o poder público, visando definir os rumos a serem tomados para o desenvolvimento econômico baseado no tripé da sustentabilidade (econômica, social e ambiental). Os países desenvolvidos que hoje apresentam elevada produção investiram e investem em pesquisas que viabilizem a produção com qualidade. O Amapá iniciou a 
produção de grãos sem um estudo prévio a respeito e sem qualquer estudo técnico-científico, e por esta razão deve-se buscar o desenvolvimento de medidas que auxiliem na produção e que desenvolvam o bioma Cerrado de maneira sustentável.

O Cerrado amapaense, segundo Costa Neto et al. (2007), apresenta várias espécies de enorme potencial para gerar renda econômica aos pequenos proprietários como as frutíferas mangaba (Hancornia speciosa Gomez.), muruci (Byrsonima crassifolia (L.) Rich.), caju (Anacardium occidentale L.) e araticum (Annona paludosa Aubl.), as medicinais barbatimão (Ouratea hexasperma (St. Hill.) Benth.), sucuúba (Himathanthus articulata (Vahl.) Wood.) e lacre (Vismia guianensis (Aubl.) Choisy).

Ainda existem as espécies arbóreas/arbustivas, segundo Costa Neto et a. (2007), que podem ser citadas sucuúba (Himathanthus articulata (Vahl.) Wood.), caimbé (Curatella americana L.), mangaba (Hancornia speciosa Gomez.), barbatimão (Ouratea hexasperma (St. Hill.) Benth.), muruci (Byrsonima crassifolia (L.) Rich.), muruci rasteiro (Byrsonima verbascifolia (L.) Rich.) e bate-caixa (Salvertia convallariaeodora St. Hill.). No estrato herbáceo as espécies mais frequentes são Chamaecrista diphylla Greene, C. racemosa (Vogel) Irwin et Barn. (Leguminosae), Comolia lytrarioides (Steud.) Naud. (Melastomataceae), Paspalum carinatum Fluegge (Poaceae), Rhynchospora barbata (Vahl) Kunth, Scleria cyperiana Kunth. (Cyperaceae). Todas estas espécies devem ser conservadas e mantidas com sua biodiversidade o mais próximo do original, para não se perder material genético importante, que futuramente podem gerar produtos com agregação de valor.

\subsection{O USO SUSTENTÁVEL DO CERRADO: MANUTENÇÃO DOS ECOSSISTEMAS E RECURSOS VEGETAIS}

Com cerca de $72 \%$ de seu território protegido por leis Estaduais e Federais que transformaram essas áreas em unidades de conservação, o Amapá tem o Cerrado como o único local para produção agrícola que não se encontra incluso totalmente sob alguma forma de proteção e que, na realidade, possui apenas uma parcela de aproximadamente 6,9\% inserida, o que possibilita seu uso para o desenvolvimento agrícola da região.

A criação de diversas Unidades de Conservação na década de 90 trouxe ao Estado do Amapá uma característica que demonstra uma imagem positiva em termos mundiais, mas que na realidade ocasiona fortes impactos à região amazônica, como por exemplo, a não inclusão do bioma Cerrado em unidades de conservação o deixa extremamente exposto a diversos tipos de uso inadequado, com elevado impacto ambiental. Um conjunto de ações políticas e econômicas tem contribuído para a formação territorial e gestão ambiental do Estado do Amapá, dentre as quais se destacam a proteção ao seu patrimônio natural com a criação de unidades de conservação, mas sem a devida bioprospecção e biogeografia para defini-las adequadamente (BRITO; PORTO, 2005).

Para Porto (2007), após a década de 1980, houve um conjunto de ações políticas e econômicas nesta Unidade Federativa que contribuíram para a sua reorganização espacial, dentre as quais se destacam: a proteção ao seu patrimônio natural com a demarcação de unidades de conservação, onde ao homem não é permitido explorar (Parque Nacional, 
Estações Ecológicas e Reservas Biológicas), Áreas de Preservação e Proteção Ambiental, juntamente com a transformação em Estado.

Com criação de novos espaços de proteção o Governo do Estado do Amapá juntamente com o Governo Federal a partir da década de 90 passou a delimitar as áreas com a criação de Áreas de Proteção Ambiental, Unidades de conservação, Parques Nacionais, Resex, entre outros tipos. Assim como, começou o processo de titulação e demarcação das terras quilombolas do território surgindo assim as Áreas quilombolas e da mesma maneira também foram delimitadas as Áreas Indígenas, sobrando pouco para a prática agropecuária que possibilite ao pequeno agricultor sobreviver.

Diante de tantas delimitações de seus espaços, em sua maioria de florestas densas, o bioma Cerrado ficou à margem destas proteções, o que acarretou seu uso para diversos fins, ou seja, muitos de seus recursos naturais foram e tem sido alvo de extinção por uso indevido através de ações antrópicas mal coordenadas e fiscalizadas. Os desafios ambientais em função do processo de urbanização identificam um campo amplo de conflitos em torno do uso e apropriação do território e dos elementos sociais bióticos e abióticos do espaço urbano (QUEIROZ, 2008).

O uso dos recursos naturais tem gerado diversos debates nos tempos atuais, como utilizar o ambiente e não gerar danos, ou melhor, de que maneira mais sustentável deve-se fazer uso destes recursos, ou seja, um desenvolvimento que conserve o solo, a água, os recursos genéticos vegetais e animais, não degrade o meio ambiente, e seja tecnicamente apropriado, economicamente viável e socialmente aceitável. Por esta razão, a isenção da prática de desenvolvimento sustentável pode orquestrar um melhor uso dos recursos naturais (SOARES, 2001, p.42) e deve ser adotada nas localidades do Cerrado onde se pretende desenvolver a agricultura em larga escala.

Para que isso ocorra é necessário que haja uma melhor gestão das áreas de Cerrado e a inclusão de parte representativa deste bioma em uma Unidade de Conservação. As Unidades de Conservação têm contribuído para a conservação da biodiversidade regional e proteção de espécies endêmicas, ameaçadas ou vulneráveis (BRAZ; CAVALCANTI, 2001). Nesse contexto, situa-se um dos termos mais mencionados nas últimas décadas: no desenvolvimento sustentável é imprescindível a inclusão da temática ambiental nos modelos de desenvolvimento que se delineiam na esfera global.

\subsection{AS POLÍTICAS PÚBLICAS PARA O DESENVOLVIMENTO DO AGRONEGÓCIO NO CERRADO AMAPAENSE}

O potencial para a agricultura é real, contudo para evitar a degradação total deste ecossistema e estimular uma produção sustentável o uso deve ser gerenciado através de políticas públicas adequadas, sendo que as existentes para a Amazônia brasileira geralmente apresentam e retratam interesses ambíguos e conflituosos, não conseguindo atingir um consenso. De um lado, busca-se o favorecimento de novas infraestruturas, suporte para o desenvolvimento econômico pautado somente na racionalidade econômica, visando apenas o favorecimento de grandes empreendimentos. De outro, políticas focadas nos interesses das

DRd - Desenvolvimento Regional em debate (ISSNe 2237-9029) 
populações locais e na sustentabilidade socioambiental, devido as pressões sociais existentes. (BECKER, 2009). Este binômio ocorre no Amapá e não tem gerado políticas públicas para o Cerrado amapaense, pois com a troca de governos estaduais o processo retorna ao seu início constantemente, apesar disso existem tentativas de fortalecer a agricultura familiar e também a agricultura empresarial, baseadas, respectivamente, na diversificação da produção e em tecnologias de ponta (ALVES; CASTRO, 2014b). Desta forma, apesar de se observar um desenvolvimento do agronegócio no Estado, o maior risco seriam a falta em pontos específicos ou a interrupção das existentes nas políticas públicas que o Estado está tentando estruturar (ALVES; CASTRO, 2014a).

Ainda faz necessário também ressaltar a importância da existência de unidades de conservação do ecossistema de Cerrado no Amapá, que passam a margem do planejamento estatal quando o assunto é desenvolvimento regional, sendo apenas exploradas como slogan de promoção de imagem política de governos sob o apelo do desenvolvimento sustentável (CHAGAS; RABELO, 2015), não havendo estudos de ordem técnica e nem de políticas públicas que possam conduzir ao desenvolvimento regional.

O zoneamento ecológico econômico (ZEE) é um importante instrumento político, que tem a função de oferecer subsídios para o processo de regulação do uso do Cerrado, integrando as diferentes políticas públicas, aumentando a eficácia da intervenção do Estado na gestão do Cerrado e na construção de parcerias. É um instrumento de planejamento econômico e gestão, estimulador do desenvolvimento sustentável (ALVES; CASTRO, 2014a), sendo que o ZEE do Cerrado amapaense ainda está sendo realizado.

O Estado possui enorme potencial, como já foi possível notar nos tópicos anteriores, para a exportação de produtos agropecuários, mas é necessário trabalhar melhor as questões de regularização fundiária, políticas públicas de gestão e controle ambiental, definindo corretamente através de um zoneamento econômico e ecológico quais as delimitações físicas das áreas que realmente poderiam ser utilizadas para cultivo (SETEC, 2014).

\section{CONCLUSÕES}

A forma de utilização do Cerrado amapaense ainda é basicamente extrativa, quando realizada pelos pequenos proprietários ou de produção de cavacos de madeira, altamente degradadora do ambiente, mas observa-se que novos tipos de uso estão surgindo, ecologicamente mais adequados. Diante desta constatação, é importante ressaltar que a crescente demanda de uso áreas deste ecossistema abre caminho para novos investimentos neste bioma e, consequentemente, novos rumos para a economia local, pois o Cerrado do Amapá tem sido alvo de novos investimentos na agropecuária. Dentre estes pode ser destacada a agricultura de escala comercial, que diferentemente da de subsistência, tem como objetivos que não é apenas de fornecer alimento para a família responsável pelo cultivo, mas sim abastecer o mercado interno, gerando excedente suficiente para exportação através do porto de Santana, gerando através dos diversos elos da cadeia produtiva os empregos de forma direta e indireta, além de aumentar a segurança alimentar estadual, por diminuir as necessidades de importação de alimentos de outras localidades, processando e agregando valor aos grãos produzidos no Cerrado amapaense.

DRd - Desenvolvimento Regional em debate (ISSNe 2237-9029) 
Para que haja um desenvolvimento regional com base em ações sustentáveis, faz-se necessário uma inserção de parte deste bioma em um programa de proteção de suas áreas, pois este encontra-se vulnerável por falta de políticas públicas que regulamentem seu uso e protejam-no do uso inadequado.

É fato que o Cerrado se apresenta como base para o desenvolvimento das práticas agrícolas, visto que tem sido utilizado para esta prática há diversos anos. A conjunção desses fatores implica que a expansão agrícola nestas áreas seguirá no futuro e certamente trará impactos tanto para este bioma quanto para os demais, particularmente a Floresta Amazônica. A conservação da biodiversidade é um tema atual e muito importante para a gestão da agricultura no Brasil. A utilização para este fim requer uma série de precauções e medidas que visem o seu desenvolvimento sustentável, sem esgotamento dos recursos naturais.

Desta forma, conclui-se que há elevado potencial para exploração de áreas do Cerrado amapaense para produção de alimentos, que tem sua área de produção com tendência de crescimento, mas é fundamental observar aspectos referentes à adoção de técnicas de manejo, uso de material genético adequado e existência de políticas públicas de gestão e fiscalização que permitam associar desenvolvimento regional com conservação ambiental, obtendo com isso uma produção sustentável.

\section{REFERÊNCIAS}

ALVES, L. W. R; CASTRO, G. S. A. Proposta de ocupação e uso agropecuário mais sustentável do cerrado amapaense: princípios, critérios e indicadores técnicos. Macapá: Embrapa Amapá, 2014a. (Embrapa Amapá. Documentos, 80).

Produção de grãos: potencial para geração de riqueza no cerrado do Estado do Amapá. Macapá: Embrapa Amapá, 2014b. (Embrapa Amapá. Documentos, 79)

BECKER, B. K. Amazônia: geopolítica na virada do III milênio. Rio de Janeiro: Garamond, 2009.

BRASIL. MMA (Ministério do Meio Ambiente). Secretaria de Biodiversidade e Florestas. Biodiversidade brasileira: Avaliação e Identificação de áreas e ações prioritárias para conservação, utilização sustentável e repartição dos benefícios da biodiversidade nos biomas brasileiros. Brasília: Ministério do Meio Ambiente, Secretaria de Biodiversidade e Florestas, 2002.

Programa Nacional de Conservação Uso Sustentável do Bioma Cerrado.

Programa Cerrado Sustentável. Brasília: MMA, 2003.

BRAZ, V. S.; CAVALCANTI, R. B. A representatividade de áreas protegidas do Distrito federal na conservação da avifauna do Cerrado. Ararajuba, Belém, v. 9, n. 1, p. 61-69. 2001.

BRITO, D. M. C.; PORTO, J. L. R. A Formação territorial e gestão ambiental no Estado do Amapá. In: ENCONTRO DE GEÓGRAFOS DA AMÉRICA LATINA; 10.; 2005, São Paulo. 
Por uma geografia latino americana: do labirinto da solidão ao espaço da solidariedade. Anais... São Paulo: Universidade de São Paulo, 2005. v. 1.

CASTRO, G. S. A. et al. Avaliação de cultivares de soja no Cerrado do Estado do Amapá. Macapá: Embrapa Amapá, 2014. 5 p. (Embrapa Amapá. Comunicado técnico, 99)

CERVO, A. L.; BERVIAN, P. A.; SILVA, R. da. Metodologia científica. 6. ed. São Paulo: Pearson Prentice Hall, 2007.

CHAGAS, M. A.; RABELO, B. V. Uma contribuição ao conhecimento da história de criação das unidades de conservação do Amapá: Amazônia Brasileira. Sustentabilidade em Debate, Brasília, v. 6, n. 2, p. 211-227, 2015.

COOPER, D. R.; SCHINDLER, P. S. Métodos de pesquisa em administração. Tradução de Luciana de Oliveira da Rocha. 7. ed. Porto Alegre: Bookman, 2011.

COSTA NETO, S. V. et al. Aspectos florísticos da Flona do Amapá e sua importância na conservação da biodiversidade. Revista Brasileira de Biociências, Porto Alegre, v. 5, p. 693695, 2007.

DOMINGUES. E. et al. (Coord.). Cobertura e uso da terra no estado do Amapá. Rio de Janeiro: IBGE, Relatório Técnico, 2004.

GIL, A. C. Métodos e técnicas de pesquisa social. 6. ed. reimp. São Paulo: Atlas, 2011.

KLINK, C. A.; MACHADO, R. B. A conservação do Cerrado brasileiro. Megadiversidade, Belo Horizonte, v.1, n.1, p.148-155. 2005.

LAKATOS, E. M.; MARCONI, M. de A. Técnicas de pesquisa: planejamento e execução de pesquisas, amostragens e técnicas de pesquisas, elaboração, análise e interpretação de dados.

5. ed. São Paulo: Atlas, 2008.

MAROUELLI, R. P. O Desenvolvimento Sustentável da Agricultura no Cerrado

Brasileiro. 2003. Brasília, Monografia (Pós-Graduação em Gestão Sustentável da Agricultura Irrigada, concentração em Planejamento Estratégico) - ISEA-FGV/ ECOBUSINESS

SCHOOL, 2003.

MATOS, P. F.; PESSÔA, V. L. S. A modernização da agricultura no Brasil e os novos usos do território. Geo UERJ, Rio de Janeiro, v. 2, n. 22, p.290-322. 2011.

MELÉM JÚNIOR, N. J. et al. Adsorção de fósforo remanescente em latossolo amarelo distrófico no cerrado do Amapá. In: SIMPÓSIO NACIONAL DO CERRADO, 9.; SIMPÓSIO INTERNACIONAL SAVANAS TROPICAIS, 2., 2008, Brasília, DF. Desafios e estratégias para o equilíbrio entre sociedade, agronegócio e recursos naturais. Anais... Planaltina, DF: Embrapa Cerrados, 2008. 1 CD-ROM.

; FARIAS NETO, J. T. de; YOKOMIZO, G. K. Caracterização dos cerrados do Amapá. Macapá: Embrapa Amapá, 2003. (Embrapa Amapá. Comunicado Técnico, 105). 
OLIVEIRA, C. P. O método de avaliação por múltiplos critérios como apoio ao planejamento ambiental: aplicação experimental no cerrado central do Amapá, Brasil. 2009. Dissertação (Mestrado em Biodiversidade Tropical) - UNIFAP, Macapá, 2009.

PEDRADA, T. I. S.; SANTOS, M. T. F. de O. Uma análise dos cenários e desafios da logística de escoamento do grão de soja do Estado do Mato Grosso em direção ao Estado do Amapá. Revista de Ciências da Amazônia, Macapá, n. 2, v. 2, p. 01-08. 2014.

PORTO, J. L. R. Amapá: principais transformações econômicas e institucionais: 1943 a 2000. Macapá: SETEC. 2007.

PPCDAP. Plano estadual de prevenção e controle do desmatamento e queimadas do estado do Amapá: contexto e ações. Coordenador Dimitrius Gabriel. Macapá Amapá, 2010. Disponível em <www.amapá.gov.br> . Acesso em: 26 dez. 2012.

QUEIROZ, S. Território Quilombola do Curiaú e área de proteção ambiental do rio Curiaú: interpretações dos conflitos sócios ambientais pela economia ecológica. 2008. Dissertação (Mestrado em Planejamento do Desenvolvimento) - Universidade Federal do Pará, Núcleo de Altos Estudos Amazônicos, Belém, 2008.

SAMPIERI, R. H.; COLLADO, C. F.; LUCIO, P. B. Metodologia de pesquisa. 5.ed. Porto Alegre: AMGH, 2013.

SANO, E. E. et al. Mapeamento semi detalhado do uso da terra do Bioma Cerrado. Pesquisa Agropecuária Brasileira, Brasília, v. 43, n. 1, p.153-156, 2008.

SANTOS, M. A. et al. O cerrado brasileiro: notas para estudo. Belo Horizonte: CEDEPLAR/FACE/UFMG; n. 387, 2010.

SETEC (Secretaria Estadual de Ciência e Tecnologia do Amapá). Mapeamento de solos e aptidão agrícola do Cerrado do Amapá. 2014 (in press).

SOARES, A. C. A multifuncionalidade da agricultura familiar. Revista Proposta, Rio de Janeiro, v. 87, p. 40-49, 2000/2001.

SUPERTI, E.; SILVA, G. V. Integração internacional e políticas públicas de defesa e segurança na fronteira setentrional Amazônica: reflexões sobre a condição fronteiriça amapaense. Revista Intellector, Rio de Janeiro, v. 11, p. 129-147. 2015.

YIN, R. K. Estudo de caso: planejamento e métodos. 4. ed. Porto Alegre: Bookman, 2010.

YOKOMIZO, G. K.-I. Y. Diagnóstico da produção de grãos no Estado do Amapá em 2011. Macapá: Embrapa Amapá, 2015. (Embrapa Amapá. Documentos, 87).

Potencialidade da Soja no Amapá. Macapá: Embrapa Amapá, 2004. (Embrapa Amapá. Documentos, 54)

Artigo recebido em: 21/03/2016

Artigo aprovado em: 02/05/2016 